\title{
DETERMINANTS OF CATTLE FARMERS PARTICIAPTION IN FARMERS ORGANIZATION IN HAMADAN PROVINCE OF IRAN
}

\section{AMIR ALAMBEIGI, SHAHPOOR ZARIFIAN, ABDOLMOTALLEB REZAEI}

\begin{abstract}
The study focused on determinants of cattle farmers particiaption in farmers organization in Hamadan province of Iran. Data was colleted from 75 randomly selected respondents with the aid of a questionnaire. Data were analyzed using percentage, mean score, analysis of variance and factor analysis. The findings revealed that the 5 factors deterring the participation were extracted. The first factor is called the individually motivated factor. It comprised 27.97 percents of the total variance as the most efficacious factor. The rest of the determinants known as the structural factor, the cultural factor, the membership factor, the coverage factor, express $17.38 \%, 12.32 \%, 7.29 \%$ and $5.85 \%$ of the total variances of the variables of the factors deterring the participation. These 5 determinants express $70.73 \%$ of the total variances of the variables. $29.27 \%$ of the variance pertain the factors or variables which have not been regarded in this research.
\end{abstract}

Key words: agricultural organizations, participation, deterring factors, Hamadan Province

\section{INTRODUCTION}

Schumacher (1973) believes that development program must involve three elements of education, population participation and the organization in order to make the best use of other resources. Generally speaking, attention to endogenous self-satisfied development blueprints is something indispensable in all the extension strategies all over the world. Population is regarded as the determinant and the goal in such strategies. People's participation in development programs plays a major role. The lack of appropriate extension formations causes the failure of the collateral ties of the agriculturalists and the practitioner institutes of the extension (Zariffian, 1382). It goes without saying that two major factors make us seek nongovernmental alternatives in agricultural extension: First, the necessity of meeting various requirements of the incrementing agriculturalists that are deprived of receiving efficacious dissemination services. Second, the limitations and the serious disorders of the financial resources, facilities, equipment, organizations' personnel, and the governmental dissemination institutes, (the source quandary)

Some of the researchers such as Maloof (1991), Contado (1991), Adehikara (1991) and Rogers (1987) believe aside from financial disorders and manage bottlenecks; the governmental dissemination can not meet the needs of the farmers and proffer extension services to the needy. Hence, we conclude that the participation of the governmental sector in the development of the dissemination activities is something indispensable. Thus the extension system requires an essential development in methodologies and strategies. Some new popular institutionalized methodologies have to be sought to solve such plights. After several decades of development endeavors with topdown approach and the results obtained in the developing countries evince that this finding has not been utilized efficaciously to find solutions for villagers in areas such as poverty, unemployment, inequality, immigration, the erosion of the natural resources, and the devastation of the manufacturing resources. According to the cognoscenti this finding has not been stable and everlasting in the development of a realistic rustic environment (Kallate rahmani, 2002).

The inefficiency of the top-down strategy has challenged the mentalities of the cognoscenti and the planers. What is today propounded as the bottom-to-top strategies is the result of the developments in the inaccurate ideas of the past about the conventional top-down strategy (Chima \& Denis, 1373); (River 1997) proposes three major developments for the future of the agricultural 
extension: first, Reconstruction and the effectuation of reforms in the dissemination systems. Second, the decentralization of the extension systems and third privatization.

There are two major politically institutionalized strategies for the reconstruction of the extant systems of agricultural extension: first, moving from a system-based structure, with organization axis and based on the administrative laws towards problem solving and the successful execution of tasks at the operational levels based on the addressees' requirements and second, the functions of the extension based on the development activities to present the extension services as consulting activities.

We dare say that some non-governmental organizations have to be formed if achievement of such objectives is required. The experiences of various countries evince that the formation of nongovernmental agricultural organizations and essential attention to their structures can obliterate most of the defects of the extant methodology of extension. FAO defines the farmer organization as a type of non-governmental formation where the agriculturalists of a specific region or the manufacturers of special goods gather to gain joint goals and have the laws, legal personality and the structure accepted by the government. These formations accept the performance of some of the government duties in the field of the agricultural services. They link agriculturalists and the government. FAO 1999 evinces a profound comprehension of the partnership usefulness and the institutionalization in the farmer organizations in the global literature. Some structures and associations are indispensable for the meaningfulness and the realization of the necessary partnership. Mac Donald (1993) says this is not a sufficient conceptualization for the organization accessories and the partnership formations. Controlling the resources and the institutes does not mean that there is an opportunity for exchanging views and making joint plans, but this is a quandary pertinent to the definition of organizations and formations, policy-devising and management. Valid organizations and institutes which can be run by the deprived villagers can be utilized to be efficacious in the vast development areas.

The aforementioned ones can be real mechanisms and manners of forming partnerships. Toosi (1372) narrates the materials of Davis and John new Strom (1986). He says" partnership is a mental, emotional and personal involvement about the group which is fomented to assist each other to access the collective objectives. They can form partnerships in accountability. There are 3 latent momentous elements in this definition: involvement, assistance and accountability. Participation means the mental and emotional involvement and is not limited sheerly to the physical endeavors. People are involved in activities in participation but partnership is not their sole skill. Participation causes people to assist each other and make them accountable. Peter Oakley and peter Marseden (1989), say participation is a means to increment the distribution of opportunities, taking part in the social decision-making, partnership in development and taking advantage of the pertinent uses. Population's participation in development is usually regarded as the active interference of people in the decision-making process inasmuch as it is effective in the population's lives (Uphoff, 1986). Collective interference means people have their own rights and they are obliged to bear responsibility in social problem-solving, mobilization of the local resources, the proposal of new solutions, the establishment and the reinforcement of the autochthonous organizations. Some of the researchers consider participation as active processes that is to say the person or the group in question acts as a pioneer and uses its own self-dependence right. Hence, this means the implementation of some organized efforts to control resources and the systematic institutes in designated social situations and they control the persons who have been exceptions to the aforementioned manipulations. Rogers (1982), says participation means the interference of the system members in the decision-making process. Participation means partnership, cooperation and collaboration. It is a type of social comportment based on the collective and individual profits and beliefs. Its general sense means mobilization of population to bear responsibility for the social and economic matters. Population's aid in the form of brain or brawn and the decentralization in the 


\section{Journal Of Agriculture and Social Research (JASR) Vol. 8, No.1, 2008}

governmental offices or organizations cause the power and decision-making resources to be transferred to lower levels such as the official autochthonous authorities, selected persona or boards in villages and small towns. The main elements of participation can be designated as follows based on the aforementioned cases:

1. Division of power and rare resources

2. The intelligent efforts of the social groups to control their destiny and to ameliorate their living conditions

3. Making opportunities for the lower classes of the society

Davis and new Strom (1995), describe two types of prerequisites in their investigation on partnership. Some of them are around population and some are inside individuals. These variables comprise appropriate time, more profit and fewer losses, personal interests, individual's ability, the collateral ties of persons, the security feeling, and not sensing any perils with regard to the profits and freedom. This is generally the expression of Special Forces which are harmonious with the autochthonous culture and coordinate with the social organization. It is indispensable to brace people's contribution. it is mandatory to have goodwill, some plans for collaborations, in the whole processes of a project. If the conditions are not ripe for their realization, these factors may act as the deterrents of the population's participation.

Tri (1986), believes that 5 chief factors deter people from participation in the development plans. These 5 factors are as follows:

1. Illiteracy and the lack of information

2. Cultural determinants

3. Lack of time for participation

4. Fearing open participations

5. Feeling suspicious of the task's final stage in other words not trusting the results.

The population participation obstacles especially the villagers have been analyzed in the development plans with disparate methodologies.

Peter Ocley and David Marsedon (1989), classify these barriers in 3 categories:

1. The practical barriers comprise the centralized planning, lack of the autochthonous coordination, irrelevancy of the projects with the requirements of the villagers and ...

2. Cultural obstacles: such as the illiteracy or the insufficient literacy of the villagers, villagers' hatred of flattering, etc

3. Structural hurdles: Oakley (1991) believes that the extant social structures can affect people's participation in disparate social and autochthonous levels

The partnership barricades are classified into 3 categories in another division:

1. Practical stumbling-blocks: the most momentous ones are as follows: noncentralized planning, the lack of autochthonous coordination, utilization of inappropriate technology in activities, executing some meaningless activities, the lack of autochthonous structures, etc

2. The cultural drawbacks: the silence culture (underworking, negligence, belief in kismet, dependence, etc)

3. Structural impediments: comprise the working environment relations, the manufacturing power, etc.

With modified of this factors, we can ensure that end-users of specific development projects are involved in developing technologies appropriate to their needs (Roth 2001:2).

We can strengthen the farmer organizations power and identify the factors deterring participation to recognize the extant situation and to make better planning in this field. Hence, the extant article has been planned based on the following goals:

The general objective of this research is the identification of the most momentous factors which deter people's participation in the activities of the agricultural organizations and the special targets are as follows: 
1. Analyzing the individual and the vocational specifications of the respondents

2. Prioritization and the determination of the factors deterring people's participation in the agricultural organizations

\section{METHODOLOGY}

The study is a descriptive survey involving members of the cattle breeders cooperative society in Hamedan province of Iran. The population fro the study was 550 members of the society out of which 75 members were selected. The simple random sampling technique was employed in the study. A questionnaire was designed and used to gather data. The data were entered into computers after the collection of the questionnaires. The validity of the factors deterring participation was calculated based on the SPSSWin13 and the Cronbach's alpha method as $0.98 \%$. Hence, it was an appropriate coefficient for the extant research. Also, 23 speeches were gathered in a systematic collection to evaluate the factors deterring the participation and the review of the resources. The addressees expressed the efficiency of the aforementioned factors in the reduction of the participation rate in a 5 partite Likret scale $(1$ meaning totally inefficient and 5 meaning totally efficient).

\section{RESULTS AND DISCUSSIONS}

\section{Demographic characteristics of the farmers.}

According to the resultant data of this research (table 1) 67 persons (89.3 percent) of the farmers are men and there are merely 8 female farmers. Considering the educational level, most of the farmers have elementary or lower degree ( 45.3 percent) and 24 persons bear lower than diploma (32 percent), 10 persons diploma (13 percent), 4 persons associate degree ( 5 percent) and the rest of them (4 percent) have bear bachelor or higher degree. The Categorization of Farmers age, most of the farmers to settle in 51- 60 years category with 40 persons (30 percent). The manner of getting acquainted with the cooperative, most of the farmers acquainted with the cooperative by the village extension worker of the region with 34 frequencies (45.3 percent).

Table1: Some of the farmers' characteristics of the cattle-breeders cooperative

\begin{tabular}{lrrr}
\hline & Frequencies & Percentage & $\begin{array}{c}\text { Cumulative } \\
\text { percentage }\end{array}$ \\
\hline Gender & & & 89.3 \\
Male & 67 & 10.7 & 100 \\
Female & 8 & & \\
age & 6 & 8 & 8 \\
Between 21- 30 & 11 & 14.7 & 22.7 \\
Between 31- 40 & 14 & 18.7 & 41.3 \\
Between 41 -50 & 30 & 40 & 81.3 \\
Between 51- 60 & 14 & 18.7 & 100 \\
Above 60 & & & \\
The level of education & 34 & 45.3 & 45.3 \\
elementary or lower & 24 & 32 & 77.3 \\
lower than diploma & 10 & 13 & 90.7 \\
diploma & 4 & 5 & 96 \\
associate & 3 & 4 & 100 \\
bachelor or higher & & & \\
The manner of getting acquainted with & & & \\
the cooperative & & & \\
\hline
\end{tabular}


Journal Of Agriculture and Social Research (JASR) Vol. 8, No.1, 2008

\begin{tabular}{lrrr}
\hline Via friends that are members of farmer & 28 & 37.3 & 37.3 \\
organization & 2 & 2.7 & 40 \\
The Islamic council of the village & 34 & 45.3 & 85.3 \\
The village extension worker of the region & 8 & 10.7 & 96 \\
Direct visit of the authorities & 3 & 4 & 100 \\
Mass media & & & \\
\hline
\end{tabular}

\section{Prioritization of the factors deterring participation:}

according to the resultant data of the respondents' views prioritization based on the standard deviation, the factors deterring the participation of the villagers comprise the lack of a partnership culture in the area, the preference of the individual's activities, the lack of sufficient power in cooperatives to do the assigned tasks, the existence of members who guide the cooperative activities, and the lack of effectuating the promises proffered to the cooperative members, have been set respectively from priority No 1 to 4 . such factors as "the lack of officials requesting villagers to participate, the untransparent objectives of the plans for the villagers, inappropriate accessibility of the cooperative among villages, the ignorance of the experts about the disparate dimensions of the farmer organizations, are among factors which have had the everlasting effect upon the participation reduction from the view of the case under study.

\section{Table 2: The prioritization of the factors diminishing the villagers' participation}

\begin{tabular}{|c|c|c|c|}
\hline $\mathrm{S} / \mathrm{N}$ & Hurdles deterring villagers participation & $\begin{array}{l}\text { Mean } \\
\text { scores }\end{array}$ & $\begin{array}{l}\text { Standard } \\
\text { deviation }\end{array}$ \\
\hline 1 & $\begin{array}{l}\text { The lack of the participation culture in the district and the } \\
\text { preference of the individual activities }\end{array}$ & 3.81 & 0.82 \\
\hline 2 & $\begin{array}{l}\text { The lack of sufficient power in the cooperatives to do the } \\
\text { assigned tasks }\end{array}$ & 3.85 & 0.88 \\
\hline 3 & The existence of members who guide the cooperative & 3.75 & 0.90 \\
\hline 4 & $\begin{array}{l}\text { Not carrying out the promises proffered to members by the } \\
\text { cooperatives }\end{array}$ & 3.68 & 0.93 \\
\hline 5 & $\begin{array}{l}\text { Lack of harmony between the objectives of villagers and the } \\
\text { cooperatives }\end{array}$ & 3.97 & 0.96 \\
\hline 6 & The higher average age of villagers & 3.84 & 0.97 \\
\hline 7 & Lack of farmer participation in the cooperative establishment & 3.73 & 0.99 \\
\hline 8 & Lack of participation need in such plans & 3.76 & 1.01 \\
\hline 9 & $\begin{array}{l}\text { Lack of the bard of directors' attention to the autochthonous } \\
\text { knowledge of the villagers }\end{array}$ & 3.77 & 1.02 \\
\hline 10 & Some people preclude the participation of others & 3.60 & 1.07 \\
\hline 11 & Lack of sufficient time to participate in the programs & 3.67 & 1.08 \\
\hline 12 & $\begin{array}{l}\text { Lack of economic variation between the members and non- } \\
\text { members }\end{array}$ & 3.84 & 1.09 \\
\hline 13 & Negative attitudes towards the fruitlessness of the programs & 3.89 & 1.10 \\
\hline 14 & Lack of the economic results due to participation in programs & 3.81 & 1.10 \\
\hline 15 & The historical background of the participation programs failure & 4.01 & 1.12 \\
\hline 16 & Low utilization of the mass media for this purpose & 2.85 & 1.17 \\
\hline 17 & Insufficient literacy of the members & 4.16 & 1.21 \\
\hline 18 & $\begin{array}{l}\text { The ignorance of the cognoscenti about disparate dimensions } \\
\text { of the farmer organizations }\end{array}$ & 3.55 & 1.22 \\
\hline 19 & Cooperatives are located inappropriately away from villages & 3.71 & 1.23 \\
\hline
\end{tabular}


Journal Of Agriculture and Social Research (JASR) Vol. 8, No.1, 2008

\begin{tabular}{llll}
\hline 20 & The lack of indispensable skills for participation & 2.95 & 1.30 \\
21 & Vague objectives of programs for farmers & 3.80 & 1.32 \\
22 & Officials not requesting villagers participation & 3.63 & 1.32 \\
23 & Officials not requesting villagers to participate & 3.40 & 1.33 \\
\hline
\end{tabular}

\section{Factor analysis:}

The factor analysis has been utilized to diminish the variables of the research to a smaller quantity and to determine the effect of each one of the factors to confine the villagers' participation. The implemented computations evince that the internal coherence of the data is appropriate $(\mathrm{KMO}=0.801)$ and Bartlet statistical data has been 1\% meaningful. According to Kaiser Criteria there are 5 factors whose special quantities have been extracted more than 1(table 3). The research variables were classified in 5 factors in accordance with Verimax methodology after the factor rotation (table 4).

Table 3: The extracted determinants along with the special quantity, variance percentage and the cumulative variance percentage

\begin{tabular}{llll}
\hline The factor No & eigenvalues & $\begin{array}{l}\text { The } \\
\text { percentage } \\
\text { eigenvalues }\end{array}$ & $\begin{array}{l}\text { variance } \\
\text { of }\end{array}$ \\
\hline 1 & 6.43 & 27.97 & $\begin{array}{l}\text { cumulative variance } \\
\text { percentage }\end{array}$ \\
2 & 3.99 & 17.38 & 27.96 \\
3 & 2.82 & 12.25 & 45.34 \\
4 & 1.68 & 7.29 & 57.58 \\
5 & 1.35 & 5.85 & 64.88 \\
\hline
\end{tabular}

Table 4: The factors deterring the villagers' participation and the variables of each factor

Factor's name

variable

The insufficient literacy of the members

Lack of adequate time to participate in programs

Negative attitude towards the fruitlessness of the programs

The individual and motivational factor

The Structural factor

The vague objectives of the programs for agriculturalists

Lack of an appropriate information conveyance system in the villages participation in programs

Lack of the indispensable skills for participation (educational feebleness)

Officials not requesting villagers
The operative burden

0.70

0.63

0.75

0.91

0.86

Lack of economic results due to 0.78

0.86 participation

Lack of farmers' participation in the cooperative establishment

0.77

Lack of harmony between the goals of the

villagers and that of the cooperative

Cooperatives not implementing promises
0.52

0.61 
proffered to the members

Lack cooperatives not having sufficient power to do the assigned tasks

The existence of members who guide the cooperative

The ignorance of the cognoscenti about disparate dimensions of the farmer 0.81 organizations

The higher average age of villagers

Lack of participation requirement in such programs

Lack of the partnership culture in the region and the preference for the solitary activities

The cultural factor The management board members not paying attention to the autochthonous knowledge of 0.73 the villagers

The people who preclude the participation of others

The membership The lack of economic variations among the factor members and nonmembers in the villages The cooperatives are situated The coverage level inappropriately away from villages factor The low utilization of mass media for this purpose

The variables of each factor have been extracted based on the table 4 and have been designated as follows:

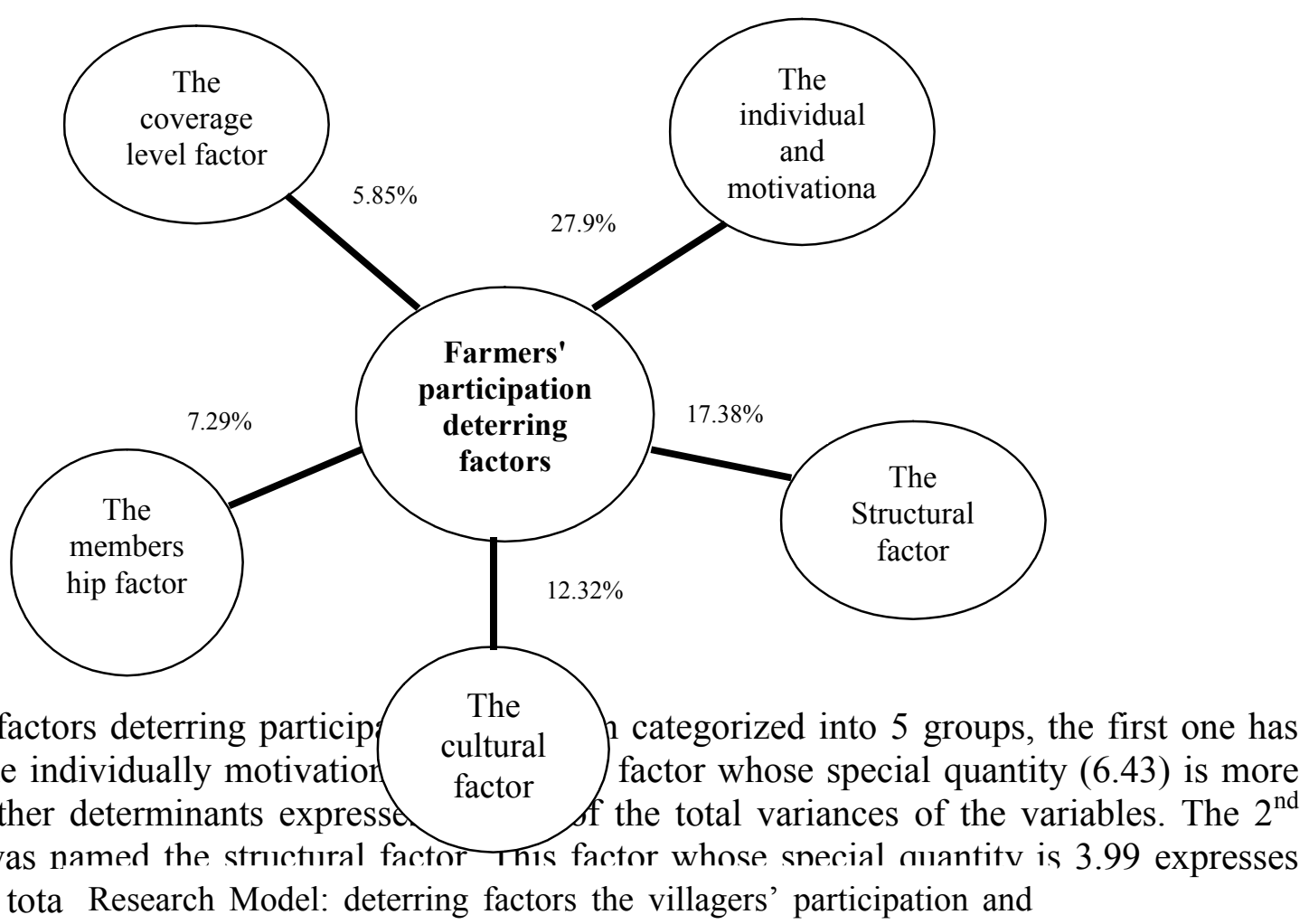

Since factors deterring particip been called the individually motivation than all the other determinants expressd The cultural categorized into 5 groups, the first one has factor factor whose special quantity (6.43) is more determinant was named the structural factor. This factor whose snecial ouantitv is 3.99 expresses $17.38 \%$ of the tota Research Model: deterring factors the villagers' participation and 


\section{Journal Of Agriculture and Social Research (JASR) Vol. 8, No.1, 2008}

The third factor was called the cultural determinant. This factor whose special quantity is 2.82 expresses $12.32 \%$ of the total variances of the variables. The $4^{\text {th }}$ factor is named the membership determinant. This factor whose special quantity is 1.68 expresses $7.29 \%$ of the total variances of the variables. The $5^{\text {th }}$ factor is called the coverage level factor. This factor whose special quantity is 1.35 expresses $5.85 \%$ of the total variances of the variables. The operational burden was a historical variable of the failure of the participation programs which was less than $50 \%$ out of the 23 variables and was deleted in the analysis. 22 structures were used to express the interference factors. As it is evident in table 3, the 7 aforementioned factors express $70.73 \%$ of the total variance of the variables. Only $29.27 \%$ of the remaining variance pertains to other factors and these portending has not come true in this analysis.

\section{CONCLUSION}

The prioritization of the deterrent factors evince that the members of the cattle-breeding cooperative think that the lack of the participation culture in the region and the preference for the individual activities are in the first priority and the lack of sufficient power in cooperatives to do the assigned tasks and the existence of members who guide the cooperative are ranked in the other priorities.

Five factors were extracted in the operational analysis of the deterrent factors where the first factor was called individually motivational and expressed $27.9 \%$ of the total variance and was introduced as the most efficacious factor. The $2^{\text {nd }}$ factor was called the structural determinant which expressed $17.38 \%$ of the total variance was presented as the most momentous factor after the first one. The rest of the factors were named the cultural factor, the membership factor, the coverage level factor, which express respectively $12.32 \%, 7.29 \%$, and $5.85 \%$, of the total variance of the variables of the factors deterring the participation. These 5 factors express totally $70.73 \%$ variances of the whole variables. Only $29.27 \%$ of the remaining variance pertains other factors (research model).

\section{RECOMMENDATIONS}

The recommendations have been presented as follows based on the results:

$>$ Since the most momentous obstacle of participation in the farmer ranking is the lack of the participation culture, making contributions to the popular formations and the development of the cultural centers and the literacy classes among the exploiters can be a significant factor for bracing such organizations. Agricultural extension must seek to brace the formation of such institutes.

$>$ Since the lack of the cooperative power to do the assigned tasks is among the momentous factors, it is proposed that the authorities and the power of such organizations should be scrutinized.

$>$ Since the fact that cooperatives not implement ting their promises is among the prioritized realities, the suggestion is to have the strategies of such institutes reviewed by the government.

$>$ Since the cultural motivational factors brace the exploiters participation, it is proposed that such cases as the necessary educations for propagators and agriculturalists be considered along with the formation of cooperatives and the clarification of the programs for farmers.

\section{REFERENCES}

FAO. (1999). Sustainable development small farmer group association: bringing the poor together. Rome, Italy.

Oakley. P (1991). Project with people: the practice of participation in rural development. Geneva. International labour office. 


\section{Journal Of Agriculture and Social Research (JASR) Vol. 8, No.1, 2008}

Oakley, P. Marsden, D. (1989). Approaches to participation in rural development. Geneva, ILO.

Rivera, M, W, (1997).” Agricultural extension into next decade". European journals of agricultural extension and education. 4 (1): 29- 38.

Rogers, E. M. (1983). Diffusion of innovations. New York: free press.

Roth, G. 2001. The position of farmers' local knowledge within agricultural extension, research, and development cooperation, in Indigenous Knowledge and Development Monitor. Hague: Nuffic- CIRAN.

Tosi, M, A. (1994). Participation, Tehran. Iran. CESM publication.

Tri, H.C. 1986. Problems and methods of institutionalizing participation, in Participate in Development. Paris: UNESCO Publishing.

Uphoff, N. (1995). "Institutionalization user participation in a system of linkage among research, extension and farmer". Workshop extension dynamics and future roles. July 4-5, 24pp.

Uphoff, N. (1986). "Approaches to participation agriculture and rural development". In M. Bamberger; Reading in community participation (Washington, D.C, Economic development institute of World Bank).

Chima, J, Shaibr and Randinly, Denis. (1994). " Implementation of Decentralization plans in Asia, local Racecourses for Rural Development" , Translate to Persian: Hakimi, Abas, Mir, javad and Zokaei, Mohammad, Tehran, Rosta va Tose Press

Kalate Rahmani, Mehdi. (2002)." Role of Farmer organization in Private Extension", the first Privatization of agricultural Extension Symposium, Tehran, Iran.

Zarifian, S. (2002). the study of farmers organization in Agricultural Sustainable Development. $\mathrm{PhD}$. Thesis University of Tehran, Iran 